Jurnal Terapung : Ilmu - Ilmu Sosial , Vol. 3, No. 2, September 2021 ISSN: 2656-2928

\title{
FAKTOR PENGHAMBAT MOTIVASI BELAJAR SISWA PADA MATA PELAJARAN MATEMATIKA DI SDN KERATON 5 MARTAPURA
}

\author{
Arif Ganda Nugroho \\ Email: arif.gnugroho@gmail.com \\ Fakultas Keguruan dan Ilmu Pendidikan Universitas Muhammadiyah Banjarmasin \\ Jalan Gubernur Sarkawi, Handil Bakti, Barito Kuala Kalimantan Selatan
}

\begin{abstract}
ABSTRAK
Motivasi belajar berarti keseluruhan daya penggerak didalam diri para siswa/warga belajar/Peserta didik yang dapat menimbulkan, menjamin, dan memberikan arah pada kegiatan belajar, guna mencapai tujuan belajar yang di harapkan. Dengan motivasi belajar, maka siswa/ warga belajar/ peserta didik dapat mempunyai intensitas dan kesinambungan dalam proses pembelajaran/ pendidikan yang di ikuti. Memotivasi pelajar merupakan salah satu langkah awal yang harus dilakukan oleh seorang guru dalam pengajaran dan pembelajaran. Jika guru telah berjaya membangun motivasi pelajar semasa pengajaran dan pembelajaran bermakna guru itu telah berjaya mengajar. Namun pekerjaan ini tidaklah mudah. Memotivasi pelajar tidak hanya menggerakkan pelajar agar aktif dalam pelajaran, tetapi juga mengarahkan dan menjadikan pelajar terdorong untuk belajar secara terus menerus, walaupun dia berada di luar kelas ataupun setelah meninggalkan sekolah.

Kata Kunci: Penghambat Motivasi Belajar, Pelajaran Matematika
\end{abstract}

\section{ABSTRACT}

Learning motivation means the overall driving force within the students/students/students that can lead to, guarantee, and provide direction to learning activities, in order to achieve the expected learning goals. With learning motivation, students/students/students can have intensity and continuity in the learning/education process that is followed. Motivating students is one of the first steps that must be taken by a teacher in teaching and learning. If the teacher has succeeded in building student motivation during teaching and learning, it means that the teacher has succeeded in teaching. But this job is not easy. Motivating students not only moves students to be active in learning, but also directs and makes students motivated to learn continuously, even though they are outside the classroom or after leaving school.

Keywords: Inhibitors of Learning Motivation, Mathematics Education

\section{PENDAHULUAN}

Upaya meningkatkan mutu pendidikan dewasa ini mengalami berbagai perubahan. Perubahan itu terjadi karena antara dunia pendidikan dan masyarakat menghendaki kesesuaian dengan tuntunan zaman. Hal tersebut sesuai dengan apa yang dicantumkan dalam Undang-Undang RI Nomor 20 Tahun 2003. Tentang Sistem Pendidikan Nasional pasal 37 yaitu: "Kurikulum disusun untuk mewujudkan tujuan Pendidikan Nasional dengan memperhatikan tahap perkembangan siswa dan kesesuaiannya dengan lingkungan kebutuhan Pembangunan Nasional, 
perkembangan ilmu pengetahuan dan teknologi serta kesenian sesuai dengan jenis dan jenjang satuan pendidikan" (Depdikbud, 1994: 1).

Siswa dalam menerima dan menyerap pengetahuan di sekolah tidak selalu berjalan dengan baik dan lancar. Hambatan dan tantangan yang dihadapi selalu saja ada sehingga menjadi problema yang dapat mengganggu proses dan hasil belajar siswa, siswa yang demikian disebut dengan siswa yang berproblema, siswa yang berproblema dapat memanifestasikannya dalam tingkah laku baik verbal maupun nonverbal pada saat belajar di dalam kelas atau di luar kelas yang pada akhirnya juga akan mempengaruhi prestasi belajarnya.

Dan uraian di atas dapat disimpulkan bahwa sekolah harus memberikan layanan bimbingan agar siswa mendapatkan prestasi belajar yang tinggi. Untuk mendapatkan prestasi belajar yang tinggi harus ada motivasi-motivasi belajar siswa.

\section{LANDASAN TEORI}

\section{A. Pengertian Motivasi Belajar}

\section{Motivasi}

Kata motivasi baerasal dari bahasa latin yaitu movere, yang berarti bergerak (move). Motivasi menjelaskan apa yang membuat orang melakukan sesuatu, membuat mereka tetap melakukannya, dan membantu mereka dalam menyelesaikan tugas-tugas. Hal ini berarti bahwa konsep motivasi digunakan untuk menjelaskan keinginan berperilaku, arah perilaku (pilihan), atau prestasi yang sesungguhnya (Pintrich,2003). Menurut Wahjosumidjo: "Motivasi adalah suatu proses psikologi yang mencerminkan interaksi antara sikap, kebutuhan, persepsi, dan keputusan yang terjadi pada diri seseorang untuk bertingkah laku dalam rangka memenuhi kebutuhan yang dirasakan." (Wahjosumidjo,1987. 174).

\section{Motivasi Belajar}

Motivasi belajar berarti keseluruhan daya penggerak didalam diri para siswa/warga belajar/Peserta didik yang dapat menimbulkan, menjamin, dan memberikan arah pada kegiatan belajar, guna mencapai tujuan belajar yang di harapkan. Dengan motivasi belajar, maka siswa/ warga belajar/ peserta didik dapat mempunyai intensitas dan kesinambungan dalam proses pembelajaran/ pendidikan yang di ikuti. Dalam kegiatan belajar, maka motivasi juga dapat dikatakan sebagai keseluruhan daya penggerak di dalam diri siswa yang menimbulkan kegiatan belajar, yang menjamin kelangsungan dari kegiatan belajar dan memberikan arah pada kegiatan belajar, sehingga tujuan yang di kehendaki oleh subjek belajar itu dapat tercapai (Sardiman, 2000).

\section{Sifat-sifat Motivasi}

Menurut Martin Handoko, sifat-sifat motivasi terdiri atas:

a. Motivasi Instrinsik,

Yaitu motivasi yang berfungsinya tidak usah dirangsang dari luar, karena memang dalam diri individu tersebut sudah ada dorongan untuk melakukan tindakan. Misalnya : murid belajar menghadapi ujian karena dia senang pada mata pelajaran yang di ujikan. Itu.murid termotivasi untuk belajar saat mereka diberi pilihan ,senang menghadapi tantangan yang sesuai dengan kemampuan 
mereka,dan mendapat imbalan yang mengandung informasional tetapi bukan dipakai untuk kontrol,misalnya guru memberikan pujian kepada siswa .

b. Motivasi Ekstrinsik,

Yaitu motivasi yang berfungsinya karena disebabkan oleh adanya faktor pendorong dari luar diri individu. (Tim MKDK IKIP Surabaya, 1995. 87). Motivasi ekstrinsik sering dipengaruhi oleh intensif eksternal seperti imbalan dan hukuman , misalnya,murid belajar keras dalam menghadapi ujian untuk mendapatkan nilai yang baik .terdapat dua kegunaan dari hadiah,yaitu sebagai insentif agar mau mengerjakan tugas ,dimana tujuannya adalah mengontrol perilaku siswa ,dan mengandung informasi tentang penguasaan keahlian.

\section{Jenis-jenis motivasi dan manfaatnya}

Jenis-jenis motivasi yang terjadi atas dasar pembentukannya menurut sardiman terbagi atas 2 (dua) jenis yaitu:

a. Motivasi bawaaan, yaitu motivasi yang dilatarbelakangi oleh fisio kemis di dalam tubuh seseorang yang telah dibawah sejak lahir dan terjadinya tanpa dipelajari.

b. Motivasi yang dipelajari, yaitu motivasi yang terjadi karena karena adanya komunikasi dan isyarat sosial serta secara sengaja dipelajari oleh manusia (Sardiman. 1992. 86)

\section{B. Guru Sebagai Penggerak Motivasi}

Sebagai seorang guru, kita memiliki berbagai tanggung jawab dan tugas yang harus dilaksanakan sesuai dengan tuntutan profesi guru.Tugas utama dan terpenting yang menjadi tanggung jawab seorang guru adalah memajukan, merangsang dan membimbing pelajar dalam proses belajar. Segala usaha ke arah itu harus dirancang dan dilaksanakan. Guru yang berkesan dalam menjalankan tugasnya adalah guru yang berjaya menjadikan pelajarnya bermotivasi dalam pelajaran. Oleh itu untuk keberkesanan dalam pengajaran, guru harus berusaha memahami makna motivasi belajar itu sendiri dan mengembangkan serta menggerakkan motivasi pemberlajaran pelajar itu ke tahap yang maksimum.

Guru dapat memahami motivasi belajar jika sewaktu mengajar dia dapat melaksanakan langkah-langkah seperti berikut:

1. Mengenal pasti tingkat kecerdasan para pelajar.

2. Melaksanakan teknik memotivasi pelajar.

3. Merumuskan tujuan belajar dan mengaitkan tujuan itu dengan keperluan dan minat pelajar.

4. Menerapkan kemahiran bertanya kepada pelajar.

5. Melaksanakan aktiviti pengajaran dengan urutan yang sistematik.

6. Melaksanakan penilaian diagnostik.

7. Melaksanakan komunikasi interpersonal.

Memotivasi pelajar merupakan salah satu langkah awal yang harus dilakukan oleh seorang guru dalam pengajaran dan pembelajaran. Jika guru telah berjaya membangun motivasi pelajar semasa pengajaran dan pembelajaran bermakna guru itu telah berjaya mengajar. Namun pekerjaan ini tidaklah mudah. Memotivasi pelajar tidak hanya menggerakkan pelajar agar aktif dalam pelajaran, tetapi juga 
mengarahkan dan menjadikan pelajar terdorong untuk belajar secara terus menerus, walaupun dia berada di luar kelas ataupun setelah meninggalkan sekolah.

\section{Faktor Penghambat Motivasi Belajar siswa}

Pemimpin adalah seseorang yang mampu mempengaruhi orang lain, dengan beberapa persyaratan, antara lain memiliki intelektualitas yang tinggi, mampu melakukan hubungan social yang baik, kematangan emosional, fisik yang baik, imajiner dan mau bekerja keras. Akan tetapi dalam kenyataan di lembaga pendidikan kita jarang dijumpai seorang guru yang memiliki criteria diatas.

Faktor-faktor yang menghambat motivasi belajar siswa, yang perlu diantisipasi dalam lembaga pendidikan kita adalah:

1. Kurangnya memadukan motivasi-motivasi kuat yang sudah ada misalnya: motivasi untuk menjadi sarjana tidak dipadukan dengan motivasi untuk menonjolkan diri yang kebetulan ada pada diri siswa agar berhasil dalam belajar.

2. Tidak adanya kejelasan tujuan yang hendak dicapai semakin jelas tujuan belajar semakin kuat motivasi untuk mencapainya, setidak-tidaknya semakin efektif berbuat. Oleh karena itu sangat ideal apabila guru merumuskan dengan jelas tujuan belajar.

3. Tidak adanya rumusan tujuan sementara. Suatu kegiatan yang mempunyai tujuan yang jauh dapat dipenggal-penggal hingga didapat tujuan sementara atau tujuan jangka pendek.

4. Kurangnya merangsang pencapaian kegiatan. Semakin dekat tujuan, semakin kuat motivasi untuk mencapainya "kedekatan tujuan" dapat dilakukan dengan membuat tujuan sementara, sebab mencapai tujuan sementara menyadarkan siswa dalam usaha mencapainya.

5. Tidak adanya situasi persaingan. Pada umumnya dalam diri setiap individu ada usaha untuk menonjolkan diri atau ingin dihargai, kecendrungan ini dapat disalurkan dalam persaingan sehat dimana guru menciptakan suasana setiap siswa giat berusaha.

6. Kurangnya menumbuhkan persaingan dengan diri sendiri siswa diberi tugas yang berbeda sehingga siswa itu sendiri yang akan melihat tugas mana yang paling baik hasilnya. Dengan demikian dia dapat mempergunakan upaya yang digunakan pada waktu mengerjakan pekerjaan yang paluing baik hasilnya.

7. Kurang maksimalnya laporan hasil yang dicapai. Apabila telah selesai pekerjaan siswa maka beritahukan hasilnya sehingga dia semakin giat mencapainya lagi dengan lebih baik. Inilah keuntungan yang utama bila hasil pekerjaan di beritahukan pada setiap orang.

8. Tidak adanya contoh yang positif dari pendidik. Guru yang mengharapkan sesuatu dari siswanya harus juga memperlihatkan yang dimintanya itu terpancang dalam diri guru. Dengan demikian siswa menilai guru tersebut bekerja baik. Hal ini menimbulkan kegairahan belajar dalam siri siswa. Lebih jelasnya, seorang guru harus mempunyai strategi pendekatan yang mampu mempengaruhi siswa dalam belajar. 


\section{METODE PENELITIAN}

Dalam penelitian ini pendekatan yang digunakan adalah pendekatan kuantitatif. Pendekatan kuantitatif yaitu pendekatan yang bertumpu pada pengumpulan data berupa angka hasil pengukuran. Oleh sebab itu data diolah secara statistik deskriptif artinya hanya menggambarkan suatu kondisi atau keadaan atau fenomena dari sebuah obyek. Yang akan digambarkan dalam penelitian ini adalah peranan guru kelas dalam menghadapi ujian kenaikan kelas dan ujian nasional kelulusan.

Metode penelitian merupakan bagian yang terpenting dalam sebuah penelitian. Menurut M. Hariwijaya dan Triton P.B (2008:51) suatu penelitian dapat berhasil dengan baik atau tidak tergantung dari data yang diperoleh. Kualitas suatu penelitian juga didukung pula oleh proses pengolahan yang dilakukan.

\section{HASIL PENELITIAN DAN PEMBAHASAN Uji coba alat penggali data}

Angket di uji coba pada 4 (empat) orang guru dan 9 (sembilan) orang siswa kelas $\mathrm{V}$ yang masih merupakan anggota populasi namun tidak menjadi sampel dalam penelitian ini. Angket uji coba disebarkan pada tanggal 1 April 2021 dan pada tanggal 2 April 2021 seluruh angket telah terkumpul seluruhnya. Butir-butir tes angket yang telah diisi oleh guru bidang studi dan siswa kelas $\mathrm{V}$ tersebut di uji coba relibilitasnya satu persatu dengan menggunakan cara korelasi boleh dua sebagai berikut :

\section{Tabel 1}

TABEL PERSIAPAN UNTUK MENCARI KORELASI ANTARA BUTIR ANGKET NOMOR GANJIL (X) DENGAN BUTIR ANGKET NOMOR GENAP (Y) UNTUK GURU

\begin{tabular}{|c|c|c|c|c|c|c|c|}
\hline $\begin{array}{l}\text { NOMOR } \\
\text { SUBYEK }\end{array}$ & $\begin{array}{c}\text { GANJIL } \\
\mathrm{X}\end{array}$ & $\begin{array}{c}\text { GENAP } \\
\mathrm{Y}\end{array}$ & $X$ & Y & $x^{2}$ & $\mathrm{y}^{2}$ & $\mathrm{x} . \mathrm{y}$ \\
\hline 1 & 22 & 21 & +2 & $+0,5$ & 4 & 0,25 & 1 \\
\hline 2 & 20 & 21 & 0 & $+0,5$ & 0 & 0,25 & 0 \\
\hline 3 & 16 & 18 & -4 & $-2,5$ & 16 & 6,25 & 10 \\
\hline 4 & 22 & 22 & +2 & $+1,5$ & 4 & 2,25 & 3 \\
\hline$\Sigma$ & 80 & 82 & 0 & 0 & -24 & 9 & 14 \\
\hline
\end{tabular}

Keterangan :

$\mathrm{X}=$ Untuk butir angket nomor ganjil

$\mathrm{Y}=$ Untuk butir angket nomor genap

$\mathrm{X}^{2}=$ Adalah deviasi antara skor rata-rata seluruh subyek dengan skor setiap subyek.

$\mathrm{Y}^{2}=$ Adalah deviasi antara skor rata-rata seluruh subyek dengan skor setiap subyek.

$\mathrm{X} . \mathrm{Y}=$ Adalah hasil kali antara $\mathrm{x}$ dan $\mathrm{y}$

Untuk mencari korelasi tersebut ( $\mathrm{r}$ x.y) adalah jumlah x.y dibagi skor jumlah $\mathrm{x}^{2}$ kali $\mathrm{y}^{2}$ dengan menggunakan rumus korelasi product Moment sebagai berikut : 


$$
\begin{gathered}
r x y=\frac{\Sigma x y}{\sqrt{\left(\Sigma x^{2}\right)\left(\Sigma y^{2}\right)}} \\
\frac{14}{\sqrt{(24)(9)}} \\
\frac{14}{\sqrt{216}} \\
\frac{14}{14,69693846}
\end{gathered}
$$

$=0,952579344 \quad$ Dibulatkan menjadi $=0,953$

Selanjutnya untuk mengubah korelasi belah dua menjadi dugaan realibilitas yang cocok untuk keseluruhan angket, maka digunakan rumus Spermar Brown, sebagai berikut

$$
2 \cdot r^{1 / 2} \frac{1 / 2}{2}
$$

rxy

$$
\begin{aligned}
& \frac{1+\mathrm{r}^{1} \frac{1}{2} 1 / 2}{2 \times 0,953} \\
& \overline{1+0,953} \\
& \frac{1,906}{1,953} \\
& 0,975934459 \text { dibulatkan menjadi } 0,976
\end{aligned}
$$

\begin{tabular}{|c|c|c|c|c|c|c|c|}
\hline $\begin{array}{l}\text { NOMOR } \\
\text { SUBYEK }\end{array}$ & $\begin{array}{l}\text { GANJIL } \\
\mathrm{X}\end{array}$ & $\begin{array}{l}\text { GENAP } \\
\mathrm{Y}\end{array}$ & $X$ & $\mathrm{Y}$ & $\mathrm{x} 2$ & $y 2$ & $\mathrm{XY}$ \\
\hline 1 & 27 & 26 & $+0,25$ & $-0,5$ & 0,0625 & 0,25 & 0,125 \\
\hline 2 & 29 & 28 & $+2,25$ & $+1,5$ & 5,0625 & 2,25 & 3,375 \\
\hline 3 & 26 & 27 & $-0,75$ & $+0,5$ & 0,5625 & 0,25 & 0,375 \\
\hline 4 & 27 & 27 & $+0,25$ & $+0,5$ & 0,0625 & 0,25 & 0,125 \\
\hline 5 & 29 & 29 & $+2,25$ & $+2,5$ & 5,0625 & 6,25 & 5,625 \\
\hline 6 & 24 & 25 & $-2,75$ & $-1,5$ & 7,0625 & 2,25 & 4,125 \\
\hline 7 & 26 & 24 & $-0,75$ & $-2,5$ & 0,5625 & 6,25 & 1,875 \\
\hline 8 & 25 & 24 & $-1,75$ & $-2,5$ & 3,0625 & 6,25 & 4,375 \\
\hline 9 & 25 & 26 & $-1,75$ & $-0,5$ & 3,0625 & 0,25 & 0,875 \\
\hline 10 & 28 & 27 & $+1,25$ & $+0,5$ & 1,5625 & 0,25 & 0,625 \\
\hline 11 & 29 & 27 & $+2,25$ & $+0,5$ & 5,0625 & 0,25 & 1,125 \\
\hline
\end{tabular}

Hasil perhitungan di atas kemudian dikonsultasikan denan tabel nilai r product moment pada $\mathrm{N}=4$, maka hasil pengujian pada taraf signifikansi $5 \%$ menunjukkan $\mathrm{r}_{0}=976$ dan $\mathrm{n}=, 950$, atau $\mathrm{r}_{0}=0,976>\mathrm{r}_{1} 0,050$

Dengan demikian maka dapat dinyatakan bahwa angket yang diujicobakan ini adalah reliabel untuk penelitian yang sesungguhnya.

\section{Tabel 2}

TABEL PERSIAPAN UNTUK MENCARI KORELASI ANTARA BUTIR ANGKET NOMOR GANJIL (X) DENGAN BUTIR ANGKET NOMOR GENAP (Y) UNTUK SISWA 
Jurnal Terapung : Ilmu - Ilmu Sosial , Vol. 3, No. 2, September 2021 ISSN: 2656-2928

\begin{tabular}{|l|l|l|l|l|l|l|l|}
12 & 26 & 28 & $+0,75$ & $+0,5$ & 0,5625 & 2,25 & 1,125 \\
\hline$\square$ & 321 & 318 & 0 & 0 & 32,2500 & 27,00 & 20,500 \\
\hline
\end{tabular}

Keterangan

$\mathrm{X}=$ Untuk butir angket nomor ganjil

$\mathrm{Y}=$ Untuk butir angket nomor genap

$\mathrm{x} 2=$ Adalah deviasi antara skor rata-rata seluruh subyek dengan skor setiap subyek

y2 = Adalah deviasi antara skor rata-rata seluruh subyek dengan skor setiap subyek

$\mathrm{xy}=$ Adalah hasil kali antara $\mathrm{X}$ dan $\mathrm{Y}$

Untuk mencri korelasi tersebut ( $\mathrm{r}$ x y) adalah jumlah x.y dibagi skor jumlah x2 kali y2 dengan menggunakan rumus korelasi Product Moment sebagai berikut :

$$
\begin{aligned}
& \text { rxy }=\frac{\sum x y}{\sqrt{\left(\sum x^{2}\right)\left(\Sigma y^{2}\right)}} \\
&=\frac{20,500}{\sqrt{(32,2500)(27)}} \\
&=\frac{20,500}{\sqrt{870,75}} \\
&=\frac{20,500}{29,50847336} \\
&=0,694715709 \\
& \text { dibulatkan menjadi } 0,695
\end{aligned}
$$

Selanjutnya untuk mengubah korelasi belah dua menjadi dugaan releabilitasi yang cocok untuk keseluruhan angket, maka digunakan rumus Sperman Brown, sebagai berikut :

$$
\begin{aligned}
\text { rxy } \quad & =\frac{2 . r^{1} /{ }_{2}{ }^{1} / 2}{1+r^{1} /{ }_{2}{ }^{1} / 2} \\
& =\frac{2 x 0,695}{1+0,695} \\
& =\frac{1,390}{1,695} \\
& =0,820058997 \\
& \text { dibulatkan menjadi } 0,820
\end{aligned}
$$

Hasil perhitungan diatas kemudian dikonsultasikan dengan table nilai r Product Moment pada $\mathrm{N}=12$, maka hasil pengujian pada taraf signifikansi $1 \%$ menunjukkan ro $=0,820$ dan $\mathrm{r} 1=0,708$, atau ro $=0,820>\mathrm{r} 1=0,708$. Dengan 
demikian maka dapat dinyatakan bahwa angket yang diujicobakan ini adalah reliable untuk penelitian yang sesungguhnya. Kemudian selanjutnya adalah memperbanyak angket sesuai dengan keperluan. Dalam hal ini jumlah responden 8 orang guru bidang studi dan 135 orang siswa kelas V SDN Keraton 5 Martapura. Setiap set yang diserahkan pada responden terdiri satu lembar pengantar angket dan satu lembar angket.

\section{Tabel 3}

REKAPITULASI PROSENTASE RATA-RATA JAWABAN GURU TENTANG MENUTUP PELAJARAN PADA SAAT PELAKSANAAN PROSES BELAJAR MENGAJAR

\begin{tabular}{|c|c|c|c|c|c|c|c|c|c|}
\hline \multirow{3}{*}{$\begin{array}{l}\text { Nomor } \\
\text { Urut }\end{array}$} & \multirow{3}{*}{$\begin{array}{l}\text { Nomor } \\
\text { Angket }\end{array}$} & \multicolumn{6}{|c|}{ Alternatif Jawaban } & \multirow{2}{*}{\multicolumn{2}{|c|}{ Jumlah }} \\
\hline & & \multicolumn{2}{|r|}{ A } & \multicolumn{2}{|c|}{$\mathrm{B}$} & \multicolumn{2}{|c|}{$\mathrm{c}$} & & \\
\hline & & $\mathrm{F}$ & $\%$ & $\mathrm{~F}$ & $\%$ & $\mathrm{f}$ & $\%$ & $\mathrm{~F}$ & $\%$ \\
\hline 1 & 10 & 2 & 25 & 6 & 75 & 0 & 0 & 8 & 100 \\
\hline 2 & 11 & 4 & 50 & 4 & 50 & 0 & 0 & 8 & 100 \\
\hline 3 & 12 & 3 & 37,50 & 5 & 62,50 & 0 & 0 & 8 & 100 \\
\hline 4 & 13 & 1 & 12,50 & 7 & 87,50 & 0 & 0 & 8 & 100 \\
\hline 5 & 14 & 3 & 37,50 & 5 & 62,50 & 0 & 0 & 8 & 100 \\
\hline 6 & 15 & 1 & 12,50 & 7 & 87,50 & 0 & 0 & 8 & 100 \\
\hline 7 & 16 & 7 & 87,50 & 1 & 12,50 & 0 & 0 & 8 & 100 \\
\hline \multicolumn{2}{|c|}{ Jumlah } & 21 & 262,50 & 35 & 437,50 & 0 & 0 & 64 & 700 \\
\hline \multicolumn{2}{|c|}{ Rata-rata } & 3 & 37,50 & 5 & 62,50 & 0 & 0 & 8 & 100 \\
\hline
\end{tabular}

Interpretasi data :

Berdasarkan Tabel di atas, tersebut diatas dapat diketahui :

a. Sebagian Kecil (37,50\%) guru bidang di SDN Keraton 5 Martapura studi mejawab selalu menutup pelajaran pada saat pelaksanakan proses belajar mengajar (PBM).

b. Cukup besar $(62,50 \%)$ guru bidang di SDN Keraton 5 Martapura studi mejawab kadang-kadang menutup pelajaran pada saat pelaksanakan proses belajar mengajar (PBM).

c. Tidak ada $(0 \%)$ guru bidang di SDN Keraton 5 Martapura studi mejawab tidak pernah menutup pelajaran pada saat pelaksanakan proses belajar mengajar (PBM). Hal ini menunjukkan wajar motivasi belajar siswa menurun.

Tabel 4

REKAPITULASI PROSENTASE RATA-RATA JAWABAN SISWA TENTANG PENGERTIAN, FUNGSI, TUJUAN DAN MANFAAT BELAJAR

\begin{tabular}{|c|c|c|c|c|c|c|c|c|c|}
\hline \multirow{3}{*}{$\begin{array}{c}\text { Nomor } \\
\text { Urut }\end{array}$} & \multirow{3}{*}{$\begin{array}{l}\text { Nomor } \\
\text { Angket }\end{array}$} & \multicolumn{6}{|c|}{ Alternatif Jawaban } & \multirow{2}{*}{\multicolumn{2}{|c|}{ Jumlah }} \\
\hline & & \multicolumn{2}{|c|}{$\mathrm{A}$} & \multicolumn{2}{|c|}{ B } & \multicolumn{2}{|c|}{$\mathrm{C}$} & & \\
\hline & & $\mathrm{F}$ & $\%$ & $\mathrm{~F}$ & $\%$ & $\mathrm{~F}$ & $\%$ & $\mathrm{~F}$ & $\%$ \\
\hline 1 & 1 & 86 & 61,42 & 50 & 25,72 & 4 & 2,86 & 140 & 100 \\
\hline 2 & 2 & 81 & 57,86 & 54 & 38,57 & 5 & 3,57 & 140 & 100 \\
\hline 3 & 3 & 93 & 66,43 & 41 & 29,29 & 6 & 4,28 & 140 & 100 \\
\hline 4 & 4 & 102 & 72,86 & 27 & 19,28 & 11 & 7,86 & 140 & 100 \\
\hline \multicolumn{2}{|c|}{ Jumlah } & 362 & 256,57 & 172 & 122,88 & 26 & 18,57 & 560 & 400 \\
\hline
\end{tabular}




\begin{tabular}{|c|c|c|c|c|c|c|c|c|}
\hline Rata-rata & 90,5 & 64,64 & 43 & 30,72 & 6,5 & 4,62 & 140 & 100 \\
\hline
\end{tabular}

Interpretasi data :

Berdasarkan Tabel di atas, tersebut diatas dapat diketahui :

a. Sebagian besar (64,64\%) siswa kelas V di SDN Keraton 5 Martapura menjawab ya tentang pengertian, tujuan, fungsi dan manfaat belajar.

b. Sebagian kecil $(34,00 \%)$ siswa kelas V di SDN Keraton 5 Martapura menjawab ragu-ragu tentang pengertian, tujuan, fungsi dan manfaat belajar.

c. Sebagian kecil (5,92\%) siswa kelas V di SDN Keraton 5 Martapura menjawab tidak tahu tentang pengertian, tujuan, fungsi dan manfaat belajar. Hal ini wajar motivasi belajar siswa menurun

\section{Tabel 5}

REKAPITULASI PROSENTASE RATA-RATA FAKTOR-FAKTOR YANG MENGHAMBAT MOTIVASI BELAJAR SISWA DARI GURU SEBAGAI PELAKSANA PBM

\begin{tabular}{|c|c|c|c|c|c|c|c|c|c|}
\hline \multirow[t]{3}{*}{$\mathrm{No}$} & \multirow{3}{*}{ Faktor $\quad$ yang } & \multicolumn{6}{|c|}{ Alternatif Jawaban } & \multirow{2}{*}{\multicolumn{2}{|c|}{ Jumlah }} \\
\hline & & \multicolumn{2}{|c|}{$\mathrm{A}$} & \multicolumn{2}{|c|}{$\mathrm{B}$} & \multicolumn{2}{|c|}{$\mathrm{C}$} & & \\
\hline & & $\mathrm{F}$ & $\%$ & $\mathrm{~F}$ & $\%$ & $\mathrm{~F}$ & $\%$ & $\mathrm{f}$ & $\%$ \\
\hline 1 & $\begin{array}{l}\text { Membuka } \\
\text { pelajaran }\end{array}$ & 6 & 75 & 2 & 25 & 0 & 0 & 8 & 100 \\
\hline 2 & $\begin{array}{l}\text { Menyampaikan } \\
\text { materi }\end{array}$ & 3,67 & 45,83 & 4 & 50 & 0,33 & 4,17 & 8 & 100 \\
\hline 3 & $\begin{array}{c}\text { Penguasaan alat } \\
\text { peraga }\end{array}$ & 4,5 & 56,25 & 3,5 & 43,75 & 0 & 0 & 8 & 100 \\
\hline 4 & $\begin{array}{l}\text { Menutup } \\
\text { pelajaran }\end{array}$ & 3 & 37,50 & 5 & 62,50 & 0 & 0 & 8 & 100 \\
\hline \multicolumn{2}{|c|}{ Jumlah } & 17,17 & 214,58 & 14,5 & 181,25 & 0,33 & 4,17 & 32 & 400 \\
\hline \multicolumn{2}{|c|}{ Rata-rata } & 4,29 & 53,65 & 3,63 & 45,31 & 0,02 & 1,04 & 8 & 100 \\
\hline
\end{tabular}

Interpretasi data :

Berdasarkan Tabel di atas, tersebut dapat diketahui tentang penghambat motivasi belajar siswa dilihat dari guru yang melaksanakan proses belajar mengajar yaitu :

a. Cukup besar $(53,65 \%)$ guru kelas V di SDN Keraton 5 Martapura melaksanakan proses belajar mengajar sesuai ketentuan yang berlaku.

b. Cukup besar (45,31\%) guru kelas V di SDN Keraton 5 Martapura kadang-kadang melaksanakan proses belajar mengajar sesuai ketentuan yang berlaku.

c. Sebagian terkecil $(1,04 \%)$ guru kelas V di SDN Keraton 5 Martapura tidak melaksanakan proses belajar mengajar sesuai ketentuan yang berlaku.

Tabel 6

REKAPITULASI PROSENTASE RATA-RATA

FAKTOR-FAKTOR YANG MENGHAMBAT MOTIVASI BELAJAR SISWA (PENGETAHUAN SISWA)

\begin{tabular}{|c|c|c|c|c|c|c|c|c|}
\hline \multirow{2}{*}{ No } & $\begin{array}{c}\text { Faktor yang } \\
\text { diteliti }\end{array}$ & \multicolumn{2}{|l|}{ Alternatif Jawaban } & \multicolumn{2}{|c|}{ Jumlah } \\
\cline { 3 - 9 } & & \multicolumn{2}{|c|}{$\mathrm{A}$} & \multicolumn{2}{|c|}{$\mathrm{B}$} & $\mathrm{C}$ & \multicolumn{2}{|c|}{} \\
\cline { 3 - 9 } & $\mathrm{F}$ & $\%$ & $\mathrm{~F}$ & $\%$ & $\mathrm{f}$ & $\%$ & $\mathrm{f}$ \\
\hline
\end{tabular}




\begin{tabular}{|l|l|c|c|c|c|c|c|c|c|}
\hline 1 & $\begin{array}{l}\text { Pengertian } \\
\text { Fungsi tujuan } \\
\text { motivasi }\end{array}$ & 90,50 & 64,64 & 43 & 30,72 & 6,5 & 4,64 & 140 & 100 \\
\hline 2 & $\begin{array}{l}\text { Pengertian } \\
\text { ruang } \\
\text { lingkup } \\
\text { materi }\end{array}$ & 91 & 65 & 42,67 & 30,47 & 6,33 & 4,53 & 140 & 100 \\
\hline 3 & $\begin{array}{l}\text { Mengingat } \\
\text { istilah hal-hal } \\
\text { tertentu }\end{array}$ & 68,67 & 49,05 & 58,67 & 41,91 & 12,67 & 9,04 & 140 & 100 \\
\hline Jumlah & 250,17 & 178,69 & 144,34 & 103,10 & 25,50 & 18,21 & 420 & 400 \\
\hline Rata-rata & 83,39 & 59,56 & 48,11 & 34,37 & 8,5 & 6,07 & 140 & 100 \\
\hline
\end{tabular}

Interpretasi data :

Berdasarkan Tabel di atas, tersebut dapat diketahui besarnya prosentasi (\%) penghambat motivasi belajar siswa dilihat dari pengetahuan siswa yaitu :

a. Cukup besar $(59,56 \%)$ siswa kelas V di SDN Keraton 5 Martapura selalu mengetahui tentang pengertian, sungsi, tujuan, manfaat, ruang lingkup yang berkaitan dengan motivasi belajar.

b. Sebagian kecil $(34,37 \%)$ siswa kelas V di SDN Keraton 5 Martapura kadangkadang mengetahui tentang pengertian, sungsi, tujuan, manfaat, ruang lingkup yang berkaitan dengan motivasi belajar.

c. Sebagian terkecil $(6,07 \%)$ siswa kelas V di SDN Keraton 5 Martapura tidak mengetahui tentang pengertian, sungsi, tujuan, manfaat, ruang lingkup yang berkaitan dengan motivasi belajar.

Tabel 7

REKAPITULASI PROSENTASE RATA-RATA FAKTOR-FAKTOR YANG MENGHAMBAT MOTIVASI BELAJAR SISWA (SIKAP SISWA)

\begin{tabular}{|c|l|c|c|c|c|c|c|c|c|}
\hline \multirow{2}{*}{$\mathrm{N}$} & \multicolumn{1}{|c|}{$\begin{array}{c}\text { Faktor yang } \\
\text { diteliti }\end{array}$} & \multicolumn{6}{|c|}{ Alternatif Jawaban } & \multicolumn{2}{c|}{ Jumlah } \\
\cline { 2 - 9 } & \multicolumn{2}{|c|}{$\mathrm{A}$} & $\%$ & $\mathrm{~F}$ & $\%$ & $\mathrm{f}$ & $\%$ & $\mathrm{~F}$ & $\%$ \\
\cline { 2 - 9 } & $\begin{array}{l}\text { Penerimaan siswa } \\
\text { terhadap } \\
\text { materi/guru } \\
\text { bidang studi }\end{array}$ & 75 & 53,57 & 61 & 43,58 & 4 & 2,85 & 140 & 100 \\
\hline 2 & $\begin{array}{l}\text { Tanggapan siswa } \\
\text { terhadap materi } \\
\text { /guru bidang studi }\end{array}$ & 84 & 60 & 55 & 39,29 & 1 & 0,71 & 140 & 100 \\
\hline 3 & $\begin{array}{l}\text { Penghargaan } \\
\text { siswa terhadap } \\
\text { pengajaran guru } \\
\text { bidang studi }\end{array}$ & 77 & 55 & 59,67 & 42,62 & 3,33 & 2,38 & 140 & 100 \\
\hline
\end{tabular}




\begin{tabular}{|l|l|c|c|c|c|c|c|c|c|}
\hline 4 & $\begin{array}{l}\text { Ketekunan siswa } \\
\text { dalam mengikuti } \\
\text { pelajaran }\end{array}$ & 53,67 & 38,33 & 79,33 & 56,67 & 7 & 5 & 140 & 100 \\
\hline Jumlah & 289,67 & 206,90 & 255,00 & 182,16 & 15,33 & 10,95 & 420 & 400 \\
\hline Rata-rata & 72,42 & 51,72 & 63,75 & 45,54 & 3,83 & 2,74 & 140 & 100 \\
\hline
\end{tabular}

Interpretasi data:

Berdasarkan Tabel di atas, tersebut dapat diketahui besarnya prosentasi (\%) penyebab terhambatnya motivasi belajar siswa dilihat sikap siswa yaitu :

a. Cukup besar (51,72\%) siswa kelas V di SDN Keraton 5 Martapura selalu memiliki sikap positif terhadap guru / materi pelajaran.

b. Cukup besar (45,54\%) siswa kelas V di SDN Keraton 5 Martapura kadangkadang memiliki sikap positif terhadap guru / materi pelajaran.

c. Sebagian terkecil $(2,74 \%)$ siswa kelas V di SDN Keraton 5 Martapura tidak memiliki sikap positif terhadap guru / materi pelajaran.

\section{KESIMPULAN}

Berdasarkan hasil pengolahan dan analisis data dengan menggunakan rumus prosentase, kemudian hasilnya menunjukkan faktor-faktor yang menghambat motivasi belajar siswa kelas V di SDN Keraton 5 Martapura yaitu sebagai berikut:

1. Jawaban guru di SDN Keraton 5 Martapura sebagai pelaksana proses belajar mengajar dapat disimpulkan:

a. Sebagian terbesar $(87,50 \%)$ guru selalu mengecek kehadiran siswa

b. Sebagian terbesar $(87,50 \%)$ guru selalu memberikan perbaikan dan pengayaan pada siswa yang nilai rendah.

c. Sebagian besar $(75 \%)$ guru selalu menguasai materi pelajaran saat mengajar.

d. Sebagian kecil $(37,50 \%$ guru menggunakan media pengajaran

e. Sebagain terkecil $(12,50 \%)$ guru selalu memeriksa P.R siswa.

f. Sebagian terkecil $(12,50 \%)$ guru selalu mengadakan perbaikan dan pengayaan.

2. Jawaban siswa kelas V di SDN Keraton 5 Martapura dapat disimpulkan:

a. Faktor pengetahuan siswa, bahwa:

1) Sebagian besar $(72,86 \%)$ siswa selalu mengetahui manfaat setelah belajar.

2) Sebagian besar $(70,00 \%)$ siswa selalu mengetahui fungsi motivasi.

3) Sebagian kecil $(26,43 \%)$ siswa selalu mengentahui pengertian motivasi belajar.

b. Faktor sikap siswa

1) Sebagian kecil $(36,43 \%)$ siswa selalu mengerjakan P.R yang diberikan guru.

2) Sebagian besar $(69,29 \%)$ siswa selalu menjawab pertanyaan yang diberikan guru.

3) Cukup besar $(57,14)$ siswa suka dengan guru yang mengajar di SDN Keraton 5 Martapura.

4) Sebagian kecil $(33,57 \%)$ siswa selalu mencatat materi pelajaran

5) Sebagian terkecil $(13,57 \%)$ siswa selalu mempelajari pelajaran sebelum diajarkan guru. 


\section{DAFTAR PUSTAKA}

Djamarah Saiful Bahri dkk. 2002. Strategi Belajar Mengajar. Jakarta: Renika Cipta

Depdikbud dan Depnaker. 1982. Pedoman Pembinaan Program Bimbingan di Sekolah. Jakarta: Depdikbud.

Depdikbud dan Depnaker. 1986. Pedoman Penyelenggaraan Administrasi Bimbingan di Sekolah. Jakarta: Depdikbud.

Erwin Adi Putranto. 2007. Matematika itu menyenangkan. Bengawan Ilmu Buchori, Ana Eqi Astuti, Erna Juliatun. 2007. Gemar Bermain Matematika. Bengawan Ilmu Hamalik. 1992. Psikologi Belajar dan Mengajar. Bandung: Sinar Baru

Hamdani Hamid dan Beni Ahmad Saebani. 2013. Pendidikan Karakter Perspektif Islam. Bandung: Pustaka Setia.

Hari Sudrajad. 2005. Manajemen Peningkatan Mutu Berbasis Sekolah. Bandung: Cipta Cekas Grafika.

Hani T Handoko. 1993 Manajemen Pendidikan. Yogyakarta: BPPE

Komalasari, Kokom. 2011. Pembelajaran Kontekstual Konsep dan Aplikasi. Bandung: PT Refika Aditama

Latifah. 2021. Perubahan Tingkah Laku Siswa Melalui Komunikasi Antar Pribadi Guru Pendidikan Agama Islam. Al Kalam Jurnal Komunikasi, Bisnis dan Manajemen. Vol.8 No. 2 Tahun 2021. e-ISSN Elektronik: 2355-3197.

Made Pidarta. 1998. Perencanaan Pendidikan Partisipatori dengan Pendekatan Sistem. Jakarta: Rineka cipta

Mudyahardjo, Redja. 2001. Pengantar Pendidikan. Jakarta: Raja Grafindo Persada.

Mugiharso, Heru. Dkk. 2004. Bimbingan dan Konseling. Semarang: UPT Unnes

Syaifullah Sagala. 2010. Manajemen Strategik Dalam Peningkatan Mutu Pendidikan. Bandung: Alfabeta

Siswoyo, Dwi. 2007. Ilmu Pendidikan. Yogyakarta: UNY Press.

Sujanto, Bedjo, 2007. Manajemen Berbasis Sekolah: Model Pengelolaan Sekolah di Era Otonomi Daerah. Jakarta: Sagung Seto 